\title{
Forecasting model of Corylus, Alnus, and Betula pollen concentration levels using spatiotemporal correlation properties of pollen count
}

\author{
Jakub Nowosad • Alfred Stach • Idalia Kasprzyk • \\ Elżbieta Weryszko-Chmielewska - Krystyna Piotrowska-Weryszko • \\ Małgorzata Puc • Lukasz Grewling - Anna Pędziszewska • \\ Agnieszka Uruska - Dorota Myszkowska - Kazimiera Chłopek • \\ Barbara Majkowska-Wojciechowska
}

Received: 31 August 2015/Accepted: 6 December 2015/Published online: 14 December 2015

(C) The Author(s) 2015. This article is published with open access at Springerlink.com

\begin{abstract}
The aim of the study was to create and evaluate models for predicting high levels of daily pollen concentration of Corylus, Alnus, and Betula using a spatiotemporal correlation of pollen count. For each taxon, a high pollen count level was established according to the first allergy symptoms during exposure. The dataset was divided into a training set and a test set, using a stratified random split. For each taxon and city, the model was built using a random forest method. Corylus models performed poorly. However,
\end{abstract}

J. Nowosad $(\varangle)$. A. Stach

Institute of Geoecology and Geoinformation, Adam Mickiewicz University, Dzięgielowa 27, 61-680 Poznań, Poland

e-mail: nowosad@amu.edu.pl

I. Kasprzyk

Department of Environmental Biology, University of

Rzeszów, Zelwerowicza 4, 35-601 Rzeszów, Poland

E. Weryszko-Chmielewska

Department of Botany, University of Life Sciences in Lublin, Akademicka 15, 20-950 Lublin, Poland

K. Piotrowska-Weryszko

Department of General Ecology, University of Life Sciences in Lublin, Leszczyńskiego 58, 20-950 Lublin, Poland

M. Puc

Department of Botany and Nature Conservation, University of Szczecin, Felczaka 3c, 71-412 Szczecin, Poland the study revealed the possibility of predicting with substantial accuracy the occurrence of days with high pollen concentrations of Alnus and Betula using past pollen count data from monitoring sites. These results can be used for building (1) simpler models, which require data only from aerobiological monitoring sites, and (2) combined meteorological and aerobiological models for predicting high levels of pollen concentration.

\author{
Ł. Grewling \\ Laboratory of Aeropalynology, Faculty of Biology, Adam \\ Mickiewicz University, Umultowska 89, 61-614 Poznań, \\ Poland
}
A. Pędziszewska · A. Uruska
Department of Plant Ecology, University of Gdańsk, Wita Stwosza 59, 80-308 Gdańsk, Poland
D. Myszkowska
Department of Clinical and Environmental Allergology, Jagiellonian University Medical College, Śniadeckich 10, 31-531 Kraków, Poland
K. Chłopek
Faculty of Earth Sciences, University of Silesia,
Będzińska 60, 41-200 Sosnowiec, Poland
B. Majkowska-Wojciechowska
Department of Immunology, Rheumatology and Allergy, Faculty of Medicine, Medical University, Pomorska 251, 92-215 Łódź, Poland 
Keywords Aerobiology - Allergenic pollen ·

Betulaceae $\cdot$ Forecast $\cdot$ Random forest .

Spatiotemporal models

\section{Introduction}

Corylus L. (hazel), Alnus Mill. (alder), and Betula L. (birch) belong to the order Fagales Engl. and the family Betulaceae Gray (Bremer et al. 2009). These trees are very common in the Northern Hemisphere (Kornas and Medwecka-Kornas 2002). The dominant species from this family in Poland are Alnus glutinosa, Alnus incana, and Betula pendula; less common are Betula pubescens, Corylus avellana, and their cultivars. The start and length of the Corylus and Alnus pollen seasons are very variable from year to year. Their pollen season in Poland usually begins some time between early February and late March and lasts on average for 30 days (Corylus) and 26 days (Alnus). The Betula pollen season occurs between the middle of April and the middle of May and lasts for approximately 18 days. Its pollen season start and duration are less variable than those of Corylus and Alnus (Nowosad et al. 2015). Furthermore, the daily and annual pollen counts of Corylus, Alnus, and Betula vary greatly (Nowosad et al. 2015).

Corylus, Alnus, and Betula pollen are well known for their allergenic properties (Viander and Koivikko 1978), and the occurrence of allergic reactions is connected with pollen concentration levels. According to Rapiejko et al. (2007), the first allergy symptoms are seen during exposure to a concentration of 35 pollen $/ \mathrm{m}^{3}$ of air for Corylus, 45 pollen $/ \mathrm{m}^{3}$ of air for Alnus , and 20 pollen $/ \mathrm{m}^{3}$ of air for Betula. Allergy symptoms in all subjects were noted at concentrations of 80,85 , and 75 pollen $/ \mathrm{m}^{3}$ of air, respectively, for Corylus, Alnus, and Betula. Sensitization rates to tree species of the family Betulaceae in Poland are high: Corylus, $22.3 \%$; Alnus, $22.8 \%$; and Betula, $27.7 \%$ (Heinzerling et al. 2009). The pollen allergens from Corylus, Alnus, and Betula are structurally and immunochemically similar. Thus, cross-reactions are very likely between allergens of the Betula family (Valenta et al. 1991).

One of aerobiology's objectives is to develop models enabling the prediction of pollen concentration in the air (Rodriguez-Rajo et al. 2006). Forecast models of pollen concentrations have many practical applications. They are highly important for allergy sufferers because predictions can allow them to undertake appropriate treatment. Models could also be useful in agriculture, forestry, and many fields of science. Most of the published results are based on the relationship between pollen season characteristics or on pollen count and meteorological conditions (Bringfelt et al. 1982; Cotos-Yáñez et al. 2004; CastellanoMéndez et al. 2005; Rodriguez-Rajo et al. 2006; Hilaire et al. 2012). Other models have been built based on an operational weather forecast system (Vogel et al. 2008) and the System for Integrated modeLling of Atmospheric coMposition (SILAM) (Sofiev et al. 2013). In Poland, Latałowa et al. (2002) delimited the major meteorological parameters as a basis for future forecast modeling of the atmospheric Betula pollen concentration in Gdańsk; Puc (2012) built an artificial neural network model of the relationship between Betula pollen and meteorological factors in Szczecin; and Myszkowska (2013) predicted Betula pollen season characteristics in Kraków.

Aerobiological surveys have been focused either on the statistical relationship between pollen count and meteorological variables or on a deterministic representation of pollen dispersion. A recent study showed that pollen counts are highly inert, temporally and spatially (Nowosad et al. 2015). Models based on this property would be relatively simple, because they do not require data other than that of pollen concentration. The forecasts would require data only from aerobiological monitoring sites and could be almost completely automated. The aim of this study was to create and evaluate Corylus, Alnus, and Betula pollen concentration level predictions based on previous pollen count values from given sites. To the best of our knowledge, there are no reports in the literature regarding how these kinds of models perform in practice.

\section{Materials and methods}

\subsection{Study area}

The studies were conducted in eight cities in Poland (Gdańsk, Kraków, Lublin, Łódź, Poznań, Rzeszów, Sosnowiec, and Szczecin) and covered six years of 
measurement (2003-2005, 2009-2011) (Fig. 1; Table 1). The measurements from years 2006-2008 were not available for all of the sites. Therefore, incomplete data were not included.

Poland is a country in Central Europe, extending $649 \mathrm{~km}$ from north to south and $689 \mathrm{~km}$ from east to west. It is a lowland country with an average elevation of $173 \mathrm{~m}$ and a surface area of $312,679 \mathrm{~km}^{2}$, only $3.1 \%$ of which is higher than an elevation of $500 \mathrm{~m}$. There are five topographic zones in Poland. The order of the zones from north to south is as follows: the Baltic coastal plains, the lake region, the central lowlands, the uplands, and the mountains (Sudeten and Carpathian ranges). Agricultural land covers approximately $60 \%$ of the surface area of the country, and forest, bush, and wooded land cover about $30 \%$. Built-up and urbanized areas occupy approximately $5 \%$ of the total area (Dmochowska 2013). All of the studied cities are agglomerations surrounded mainly by forests and farmlands. However, the proportion of land use classes around each city is different. Gdańsk lies on the coast of the central Baltic Sea, with sea to the east and agricultural lands or forests to the west and south; Szczecin is located between Dabie Lake to the northeast, forests to the southeast, and agricultural areas to the southwest; Poznań and Łódź are surrounded by forests and agricultural areas; Lublin is surrounded by agricultural areas; Rzeszów lies between forests to the north and agricultural areas to the south, east, and west; Kraków and Sosnowiec are distinguished by a larger proportion of urban areas.

Poland has a temperate continental climate. The effects of Atlantic masses of air and the proximity of the Baltic Sea are felt in Gdańsk and Szczecin. Poznań, Łódź, Sosnowiec, and Kraków are located in a transition zone between oceanic and continental air masses. The climate of Rzeszów and Lublin is influenced by continental air masses. In addition, Kraków, Sosnowiec, and Rzeszów lie near the Carpathian Mountains, which affect their climate (Blazejczyk 2006). A two-sample Kolmogorov-Smirnov test yielded no significant differences $(D=0.08$,

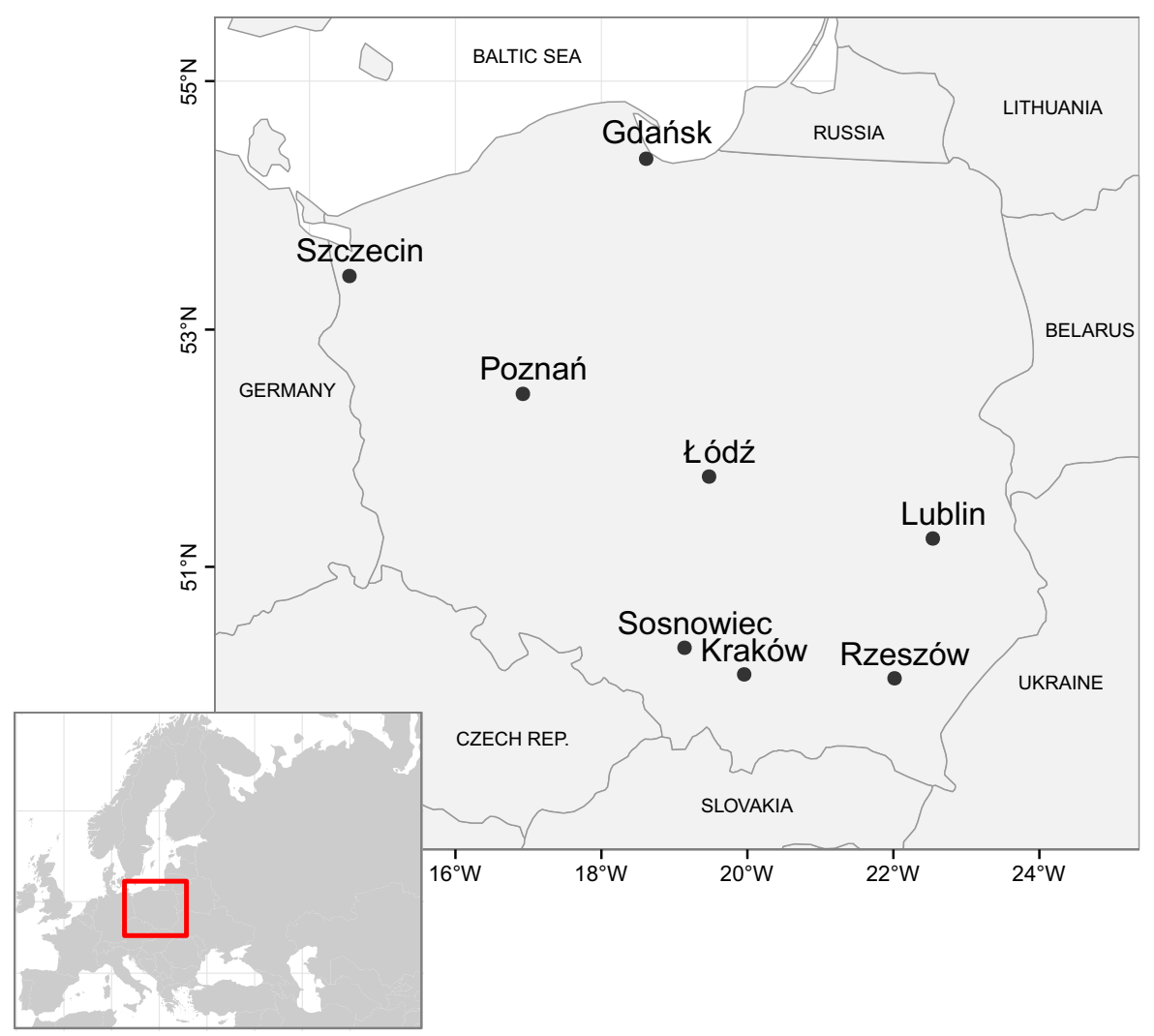

Fig. 1 The location of the sites used for the study of pollen concentration levels prediction 
Table 1 Characteristics of the study sites: latitude, longitude, and altitude of the aerobiological monitoring sites; population of the cities; and mean temperatures recorded at local meteorological stations

\begin{tabular}{|c|c|c|c|c|c|c|c|c|c|}
\hline \multirow[t]{2}{*}{ City } & \multirow[t]{2}{*}{$\lambda(\mathrm{DD})$} & \multirow[t]{2}{*}{$\phi(\mathrm{DD})$} & \multirow{2}{*}{$\begin{array}{l}\text { Altitude } \\
\text { (a.s.1.) }\end{array}$} & \multirow{2}{*}{$\begin{array}{l}\text { Population } \\
\text { (in thousands) }\end{array}$} & \multicolumn{5}{|c|}{ Mean temperature $\left({ }^{\circ} \mathrm{C}\right)(1983-2012)$} \\
\hline & & & & & Annual & January & February & March & April \\
\hline Gdańsk & 18.6131 & 54.3856 & 10 & 460 & 7.42 & -1.40 & -1.40 & 1.78 & 6.66 \\
\hline Kraków & 19.9559 & 50.0637 & 212 & 758 & 8.47 & -1.90 & -1.11 & 3.12 & 8.94 \\
\hline Lublin & 22.5402 & 51.2437 & 198 & 348 & 7.81 & -2.66 & -2.22 & 1.93 & 8.31 \\
\hline Łódź & 19.4748 & 51.7715 & 216 & 719 & 8.43 & -1.62 & -1.05 & 2.80 & 8.76 \\
\hline Poznań & 16.9243 & 52.4671 & 91 & 551 & 8.96 & -0.62 & -0.18 & 3.59 & 9.08 \\
\hline Rzeszów & 22.0160 & 50.0293 & 209 & 182 & 8.46 & -2.10 & -1.28 & 2.87 & 8.79 \\
\hline Sosnowiec & 19.1389 & 50.2972 & 252 & 214 & 8.47 & -1.50 & -0.81 & 3.08 & 8.72 \\
\hline Szczecin & 14.5478 & 53.4395 & 30 & 409 & 8.96 & 0.18 & 0.57 & 3.74 & 8.60 \\
\hline
\end{tabular}

$p$ value $=0.17)$ between the daily temperatures for the six years of the study (2003-2005, 2009-2011) and a 30-year time series of measurements (1983-2012).

\subsection{Aerobiological data}

Daily average pollen counts were measured by a volumetric spore trap of the Hirst design (Hirst 1952), according to the recommendations of the European Aerobiology Society's Working Group on Quality Control Galán et al. (2014). Traps were located $12 \mathrm{~m}$ above ground level (Rzeszów) or higher. Two different pollen counting methods were used. Pollen grains were counted along 12 vertical transects using the methods outlined by Stach (2000) (Gdańsk and Rzeszów), or along four horizontal transects using the method recommended by the Spanish Aerobiology Network (Kraków, Lublin, Łódź, Poznań, Sosnowiec, Szczecin) (Galán et al. 2007). Cariñanos and Emberlin (2000) reported that both methods follow similar trends and provide close approximations to the pollen count from the entire slide. The pollen concentration was expressed as the number of grains $/ \mathrm{m}^{3}$ of air per $24 \mathrm{~h}$ (Comtois 1998).

\subsection{Dataset creation}

All the calculations were carried out using R software packages (R Core Team 2014; Kuhn 2014; Liaw and Wiener 2002). The pollen season limits of Corylus, Alnus, and Betula at each location and for each year were calculated using the $90 \%$ method (Nilsson and Persson 1981). In this method, a season starts when $5 \%$ of the total catch has been achieved and ends when $95 \%$ has been reached. For each taxon, the earliest day of pollen season start and the latest day of pollen season end based on all of the data were used as the temporal scope.

The aim of this work was to forecast the pollen count level of allergenic risk. For each taxon, two levels of concentration were distinguished: low and high. The ranges of concentration level values were different for each taxon. The concentration levels were as follows: Corylus, low $0-35$ grains $/ \mathrm{m}^{3}$ and high $>35$ grains $/ \mathrm{m}^{3}$; Alnus, low 0-45 grains $/ \mathrm{m}^{3}$ and high $>45$ grains $/ \mathrm{m}^{3}$; and Betula, low 0-20 grains $/ \mathrm{m}^{3}$ and high $>20$ grains $/ \mathrm{m}^{3}$ (Table 2). Threshold values were based on first symptom values for patients allergic to these taxa (Rapiejko et al. 2007).

\subsection{Statistical modeling}

By using a stratified random split to divide the datasets, the distribution of the outcome in the training and test sets was preserved. Two subsets were created:

- Training set, used for training a model and choosing its optimal parameters (2/3 of cases)

- Test set, used only to evaluate the model on data not present during previous stages ( $1 / 3$ of cases)

Most of the machine learning algorithms expect equal instances of each class. Thus, the imbalance between classes can have a significant impact on the quality of the model. The dataset was slightly imbalanced in the case of Betula, and highly imbalanced for Corylus and Alnus (Table 2). Up-sampling was used to reduce this class imbalance. This technique imputes additional data to improve balance across the classes. Training 
Table 2 Absolute and relative number of days with given pollen concentration levels for the individual taxa and location

\begin{tabular}{llcc}
\hline Taxon & City & Low & High \\
\hline Corylus & Gdańsk & $432(98.63 \%)$ & $6(1.37 \%)$ \\
Corylus & Kraków & $404(92.24 \%)$ & $34(7.76 \%)$ \\
Corylus & Lublin & $395(90.18 \%)$ & $43(9.82 \%)$ \\
Corylus & Łódź & $421(96.12 \%)$ & $17(3.88 \%)$ \\
Corylus & Poznań & $420(95.89 \%)$ & $18(4.11 \%)$ \\
Corylus & Rzeszów & $413(94.29 \%)$ & $25(5.71 \%)$ \\
Corylus & Sosnowiec & $406(92.69 \%)$ & $32(7.31 \%)$ \\
Corylus & Szczecin & $406(92.69 \%)$ & $32(7.31 \%)$ \\
Alnus & Gdańsk & $344(89.58 \%)$ & $40(10.42 \%)$ \\
Alnus & Kraków & $334(86.98 \%)$ & $50(13.02 \%)$ \\
Alnus & Lublin & $310(80.73 \%)$ & $74(19.27 \%)$ \\
Alnus & Łódź & $332(86.46 \%)$ & $52(13.54 \%)$ \\
Alnus & Poznań & $308(80.21 \%)$ & $76(19.79 \%)$ \\
Alnus & Rzeszów & $332(86.46 \%)$ & $52(13.54 \%)$ \\
Alnus & Sosnowiec & $333(86.72 \%)$ & $51(13.28 \%)$ \\
Alnus & Szczecin & $292(76.04 \%)$ & $92(23.96 \%)$ \\
Betula & Gdańsk & $111(50 \%)$ & $111(50 \%)$ \\
Betula & Kraków & $80(36.04 \%)$ & $142(63.96 \%)$ \\
Betula & Lublin & $88(39.64 \%)$ & $134(60.36 \%)$ \\
Betula & Łódź & $96(43.24 \%)$ & $126(56.76 \%)$ \\
Betula & Poznań & $71(31.98 \%)$ & $151(68.02 \%)$ \\
Betula & Rzeszów & $105(47.3 \%)$ & $117(52.7 \%)$ \\
Betula & Sosnowiec & $100(45.05 \%)$ & $122(54.95 \%)$ \\
Betula & Szczecin & $79(35.59 \%)$ & $143(64.41 \%)$ \\
\hline & & &
\end{tabular}

sets were sampled with replacements to create equal class distribution. All of the original training data were left intact, and additional samples were added to the minority classes with replacements. However, the test sets were not changed, since they should reflect the class imbalance. This is important to obtain reliable estimates of a model's performance (Kuhn and Johnson 2013).

Previous research in Poland showed that there is usually an increase-delayed on average by 1-3 days - in the correlation of pollen count between the pairs of monitoring sites (Nowosad et al. 2015). This is due mainly to prevailing winds from the west toward the east in this latitude zone of the Northern Hemisphere (Rossby waves) and the movement of atmospheric fronts. Levels of Corylus, Alnus, and Betula pollen concentration were used as the outcome data. The independent variables were the previous 4 days' pollen counts from all of the sites:

$$
\begin{aligned}
& \text { PollenConcentrationLevel }_{\text {site }_{t}} \sim \text { PollenCount }_{\text {siteA }_{t-1}} \\
& \quad+\text { PollenCount }_{\text {siteA }_{t-2}}+\text { PollenCount }_{\text {siteA }_{t-3}} \\
& \quad+\text { PollenCount }_{\text {site }_{t-4}}+\text { PollenCount }_{\text {siteB }_{t-1}}+\cdots \\
& \quad+\text { PollenCount }_{\text {site }_{t-4}}
\end{aligned}
$$

Random forest (Breiman 2001) was used to predict the pollen concentration levels of Corylus, Alnus, and Betula. Preliminary studies showed that a random forest model's performance is comparable to other techniques, such as support vector machines and boosting trees. Furthermore, valuable information about random forest results could be obtained using, for example, variable importance. A random forest model has one tuning parameter: the number of randomly selected predictors to choose from at each split $\left(m_{\text {try }}\right)$. A total of 100 iterations of the bootstrap were applied as the re-sampling scheme to select the optimal values of the model's tuning parameter. A series of models were fit to the training sets. For each model, the optimal parameter value was obtained based on specificity: the rate that days with high concentration were predicted correctly:

$$
\text { Specificity }=\frac{\mathrm{CP}_{\text {high }}}{\mathrm{All}_{\text {high }}}
$$

where $\mathrm{CP}_{\text {high }}$ is the number of correctly predicted days with high concentration and $\mathrm{All}_{\text {high }}$ is the total number of days of high concentration.

The general effect of predictors on each model was calculated. Variable importance was estimated by looking at the increase in prediction error when data for a given variable were changed, while all the other variables remained constant (Breiman 2002; Liaw and Wiener 2002). Afterward, the variable importance was scaled to values between 0 and 100 .

\subsection{Evaluation of the models' performance}

The final 24 models ( 3 taxa $\times 8$ cities) were applied to generate predictions based on the test sets. Model predictions were then compared with the observed data in the test sets. A confusion matrix, unweighted Kappa statistic, sensitivity, specificity, and balanced accuracy were used to describe the performance of the models. The Kappa statistic is: 


$$
\mathrm{Kappa}=\frac{\mathrm{O}-\mathrm{E}}{1-\mathrm{E}}
$$

where $O$ is the observed accuracy and $E$ is the accuracy expected to be achieved based on the marginal totals of the confusion matrix. The Kappa statistic ranges from -1 to 1 . A value of 0 indicates no agreement between the observed and predicted classes, while a value of 1 indicates perfect agreement. Negative values rarely occur and indicate that "the prediction is in the opposite direction of the truth" (Kuhn and Johnson 2013). The sensitivity is defined as the rate that days with low concentration are predicted correctly:

Sensitivity $=\frac{\mathrm{CP}_{\text {low }}}{\mathrm{All}_{\text {low }}}$

where $\mathrm{CP}_{\text {low }}$ is the number of correctly predicted days with low concentration and $\mathrm{All}_{\text {low }}$ is the total number of days with low concentration.

Balanced accuracy helps to reduce the impact of imbalanced classes on a model's evaluation. It is defined as follows:

Balanced accuracy $=\frac{\text { Sensitivity }+ \text { Specificity }}{2}$

Additionally, Mann-Whitney $U$ test (Mann and Whitney 1947) was used to compare the weather conditions (precipitation and temperature) between true and false predictions of low and high pollen concentration levels of Corylus, Alnus, and Betula.

\section{Results}

\subsection{Model}

The start of the earliest Corylus pollen season was on day 36 of the year, and its latest season end was on day 110 of the year. For Alnus, these start and end dates ranged from days 46 to 111 of the year, and for Betula they ranged from days 97 to 135 of the year. Data only from these periods were used for model creation and evaluation (Fig. 2).

Twenty-four final models were created. Table 3 shows a summary of model results for training sets. Most (13 of 16) Corylus and Alnus models had a specificity value equal to 1 . Only in the cases of
Lublin, Poznań, and Szczecin was the Alnus model's specificity slightly lower: $0.99,0.99$, and 0.97 , respectively. Kappa statistics were also very high for the Alnus and Corylus models, with values ranging from 0.90 (for Alnus in Szczecin) to 0.99 (for Corylus in Gdańsk and Łódź). Model performance values based on the Betula training datasets were lower. However, in the majority of the models, the specificity values were still very high: between 0.81 for Gdańsk and 0.91 for Kraków. Kappa values varied noticeably, from 0.61 for Gdańsk to 0.84 for Kraków.

\subsection{Variable importance}

Variable importance for Corylus, Alnus, and Betula models shared similar temporal and spatial properties. The values of pollen counts from one day before were the most important variable, while the values from 4 days before were the least. Moreover, variables from the same site were the most important in the majority of the models.

For six of eight of the Corylus models, the most important variable was the pollen count from one day (Gdańsk, Lublin, Sosnowiec, and Łódź) or 2 days (Poznań) before. Only in the case of models of pollen concentration levels in Kraków and Rzeszów was the most important independent variable from a different city: Sosnowiec in both cases. In Corylus models, the low importance of pollen concentration inputs from 4 days before was noticeable (Figs. 3, 6).

Variable importance for Alnus models was the least uniform. Only in half of the models (Lublin, Poznan, Rzeszów, and Szczecin) was the most important variable from the same city as the output. Also, in four of eight models (Poznań, Łódż, Kraków, Sosnowiec), the most important variable was the pollen count in Poznań from one day before. Exceptionally, the most important variable for predicting pollen concentration levels in Gdańsk was data from Sosnowiec. The low impact of variables from 4 days before was also apparent (Figs. 4, 6).

Variable importance for Betula models showed some regularities. In six of eight models, the most important variables were pollen concentration from a day before at the same site as the outcome. In addition, the pollen count values at the same site from 2 to 3 days before had a visible influence. The order of variable importance was different in two models. The most important variable for the Betula model in 
Fig. 2 Pollen count of Corylus, Alnus, Betula by day of year for all of the analyzed sites in years 2003-2005 and 2009-2011 on a logarithmic scale. Vertical lines indicate the temporal scope of analysis for each taxon. Horizontal lines separate the two pollen concentration levels of low and high: $\left(35 \mathrm{~g} / \mathrm{m}^{3}\right.$ for Corylus, $45 \mathrm{~g} / \mathrm{m}^{3}$ for Alnus, $20 \mathrm{~g} / \mathrm{m}^{3}$ for Betula)
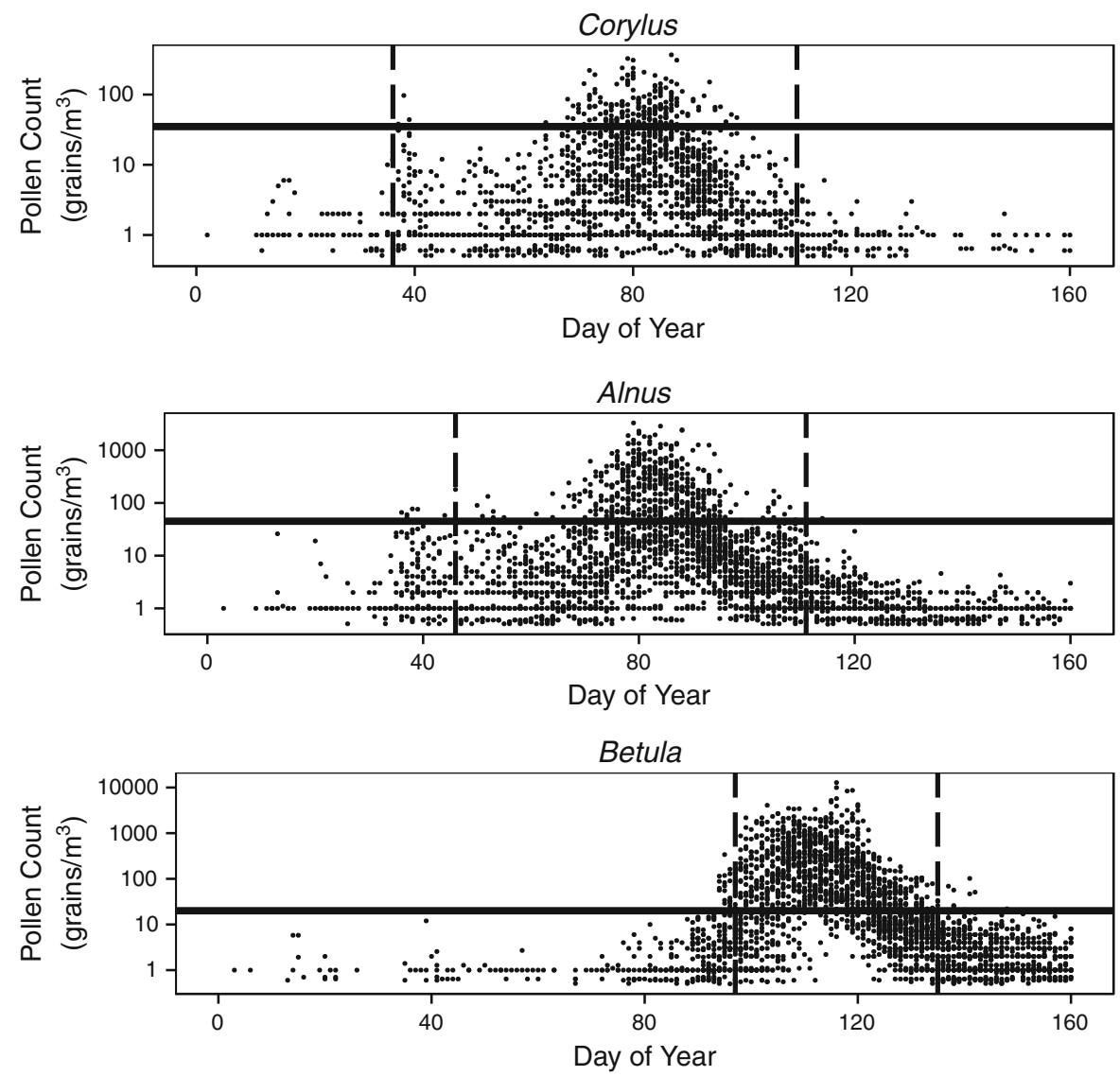

Sosnowiec was the pollen concentration value in Kraków from one day before; and the pollen concentration value in Poznań from one day before was the most important variable for the Szczecin model. Moreover, models for Gdańsk and Lublin were built based mainly on the values from the same site. In the rest of the models, many independent variables were important. Inputs from Gdańsk also had a small impact on the rest of the models. In addition, for most of the models, variables from 4 days before had either little importance or no importance at all (Figs. 5, 6).

\subsection{Performance of the models}

A confusion matrix, Kappa statistic, sensitivity, specificity, and balanced accuracy were used to evaluate the models on the test sets (Fig. 7; Table 4). Corylus models showed the lowest Kappa values. In two cases (Gdańsk and Poznań), Kappa statistics were equal to 0 . Only the model of Lublin had a substantial Kappa value (0.68).; it correctly predicted 10 of 14 cases with a high pollen concentration (Fig. 7; Table 4).

The Kappa statistics also proved important for Alnus models, with an average value of 0.7 . The minimum Kappa value was for the Gdańsk model (0.6), and the maximum was for the Łódź model (0.86). However, most of the Alnus models had a specificity lower than the Betula models. Only models for Lublin and Łodź specificity exceeded 0.8 ( 0.88 , 0.82 , respectively). The lowest specificity was found for the model for Gdańsk: 0.54 . For the test set, the model of pollen concentration group of Gdańsk predicted correctly only 7 of 13 cases of high pollen concentration (Fig. 7; Table 4).

Based on th given criteria, models of Betula were the most reliable. Their average Kappa was 0.73 , with a minimum value of 0.62 for Szczecin and a maximum of 0.81 for Kraków and Sosnowiec. Moreover, all of the specificity values for Betula models exceeded 0.8 . In all of the Betula models, specificity values were higher than the Kappa statistic (Fig. 7; Table 4). 
Table 3 A summary of Corylus, Alnus, and Betula models results for training set at each location

\begin{tabular}{|c|c|c|c|c|c|}
\hline Taxon & City & Kappa & Accuracy & Sensitivity & Specificity \\
\hline Corylus & Gdańsk & 0.99 & 1.00 & 0.99 & 1.00 \\
\hline Corylus & Kraków & 0.97 & 0.99 & 0.97 & 1.00 \\
\hline Corylus & Lublin & 0.96 & 0.98 & 0.96 & 1.00 \\
\hline Corylus & Łódź & 0.99 & 1.00 & 0.99 & 1.00 \\
\hline Corylus & Poznań & 0.98 & 0.99 & 0.98 & 1.00 \\
\hline Corylus & Rzeszów & 0.98 & 0.99 & 0.98 & 1.00 \\
\hline Corylus & Sosnowiec & 0.97 & 0.98 & 0.97 & 1.00 \\
\hline Corylus & Szczecin & 0.98 & 0.99 & 0.98 & 1.00 \\
\hline Alnus & Gdańsk & 0.94 & 0.97 & 0.94 & 1.00 \\
\hline Alnus & Kraków & 0.97 & 0.98 & 0.97 & 1.00 \\
\hline Alnus & Lublin & 0.92 & 0.96 & 0.93 & 0.99 \\
\hline Alnus & Łódź & 0.94 & 0.97 & 0.95 & 1.00 \\
\hline Alnus & Poznań & 0.91 & 0.96 & 0.93 & 0.99 \\
\hline Alnus & Rzeszów & 0.94 & 0.97 & 0.95 & 1.00 \\
\hline Alnus & Sosnowiec & 0.96 & 0.98 & 0.96 & 1.00 \\
\hline Alnus & Szczecin & 0.90 & 0.95 & 0.93 & 0.97 \\
\hline Betula & Gdańsk & 0.61 & 0.81 & 0.81 & 0.81 \\
\hline Betula & Kraków & 0.84 & 0.92 & 0.94 & 0.91 \\
\hline Betula & Lublin & 0.82 & 0.91 & 0.92 & 0.90 \\
\hline Betula & Łódź & 0.81 & 0.90 & 0.91 & 0.90 \\
\hline Betula & Poznań & 0.81 & 0.91 & 0.94 & 0.88 \\
\hline Betula & Rzeszów & 0.77 & 0.89 & 0.88 & 0.90 \\
\hline Betula & Sosnowiec & 0.71 & 0.86 & 0.85 & 0.87 \\
\hline Betula & Szczecin & 0.74 & 0.87 & 0.91 & 0.84 \\
\hline
\end{tabular}

True and false predictions were compared with temperature and precipitation. The results indicated that the rainfall was connected with a false prediction of high level in Alnus ( $p$ value $=0.0018$ ) and Betula $(p$ value $=0.0000002)$ models. However, this relation was not found in Corylus ( $p$ value $=0.12$ ) models. Additionally, true and false predictions were compared to the day-to-day changes in precipitation and temperature. The results showed that the final models were robust to changes in the precipitation; however, predictions of high level of Corylus ( $p$ value $=$ 0.0016), Alnus $(p$ value $=0.01)$, and Betula ( $p$ value $=0.001)$ are sensitive to the changes in temperature.

\section{Discussion}

One of the main goals in aerobiological models is to predict pollen concentration levels which can trigger the onset of allergic symptoms. Stepwise multiple regression (Bringfelt et al. 1982; Myszkowska 2013), additive logistic models, partially linear models (Cotos-Yáñez et al. 2004), artificial neural networks (Castellano-Méndez et al. 2005), ARIMA models (Rodriguez-Rajo et al. 2006), and stochastic gradient boosting (Hilaire et al. 2012) have been used in aerobiological studies aimed at pollen concentration prediction. Most pollen predictive modeling studies have focused on the impact of meteorological variables (such as temperature, humidity, precipitation, wind direction, and speed), on pollen season start and duration, and on pollen concentration (Bringfelt et al. 1982; Cotos-Yáñez et al. 2004; Castellano-Méndez et al. 2005; Rodriguez-Rajo et al. 2006; Hilaire et al. 2012; Myszkowska 2013). Only Castellano-Méndez et al. (2005) attempted to forecast the level of allergenic risk associated with Betula using previous Betula pollen and meteorological information. However, to the best of our knowledge, empirical predictive models have not used pollen count values from other sites before now. Previous research shows that 


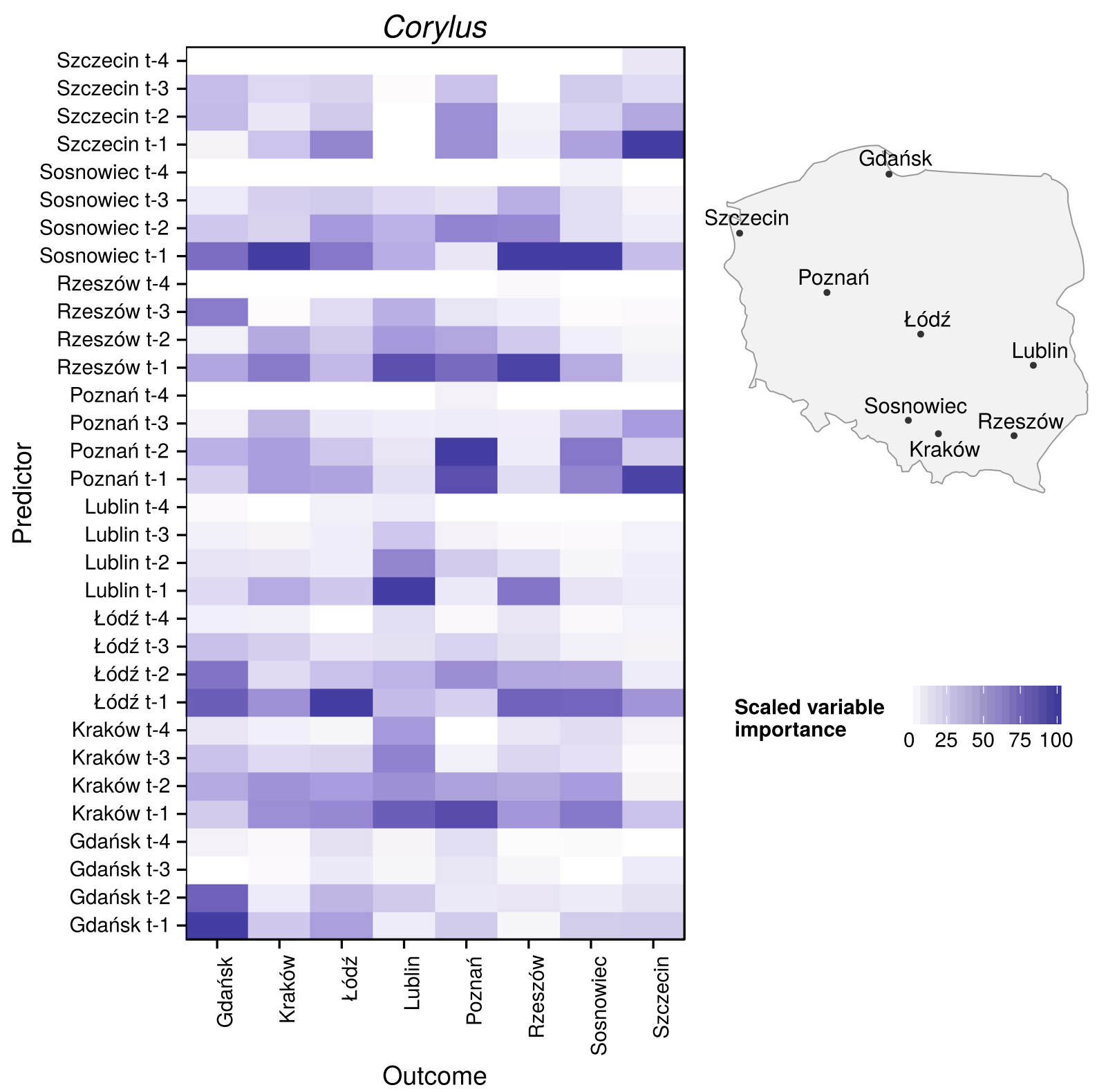

Fig. 3 Scaled variable importance of each predictor (pollen count data with 1-day lag $(t-1)$, 2-day lag $(t-2)$, 3-day lag $(t-3)$, 4-day lag $(t-4)$ at given sites) for Corylus in each

Corylus, Alnus, and Betula pollen concentration are correlated not only in time, but also in space (Nowosad et al. 2015).

Nowadays, daily pollen concentration data are a result of manual pollen counting. Thus, information about the pollen count from the previous day is not available fast enough to be used for predicting levels of pollen concentration. However, there are many location. For better spatial relations recognition, a schematic map with measurement sites was provided

efforts to create a semiautomatic and automatic systems for counting airborne pollen (Boucher et al. 2002; Holt and Bennett 2014). As a result of these studies, it should be possible to obtain information about the pollen data from the day before quickly enough to be used by a forecast system.

In this study, random forest (Breiman 2001) was used to predict the pollen concentration level of 


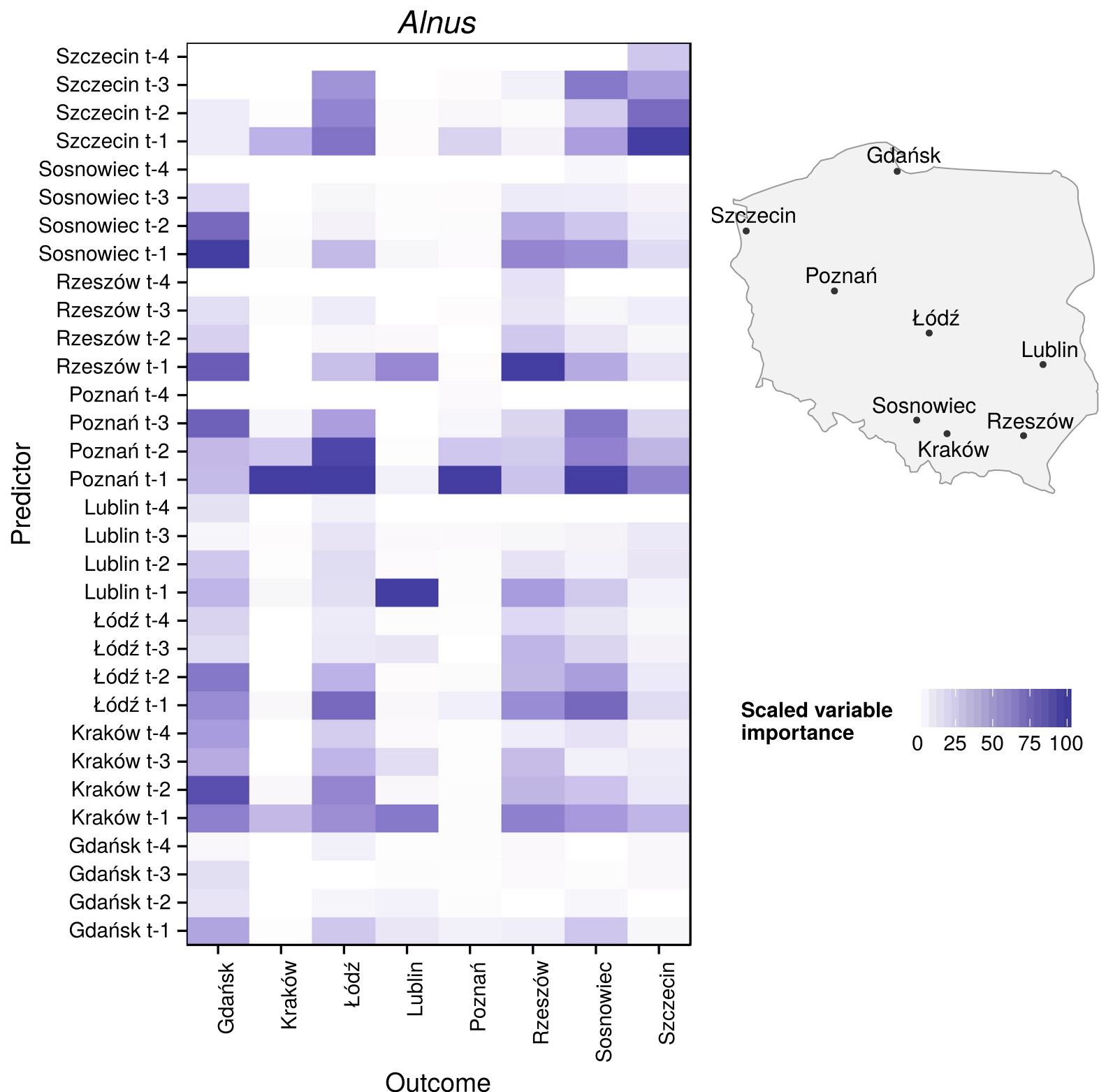

Fig. 4 Scaled variable importance of each predictor (pollen count data with 1-day lag $(t-1), 2$-day lag $(t-2), 3$-day lag $(t-3)$, 4-day lag $(t-4)$ at given sites) for Alnus in each

Corylus, Alnus, and Betula using a spatiotemporal correlation of pollen count values at the given sites. The use of random forest presents a distinct advantage with respect to classical statistical methods: the ability to process complex, nonlinear relationships between predictors (Recknagel 2001). The algorithm of random forest is based on the ensemble of a large number of decision trees (Breiman 2001). Consequently, random forest has the advantage of tree-based models location. For better spatial relations recognition, a schematic map with measurement sites was provided

over artificial neural networks or support vector machines: interpretability (Geurts et al. 2009). A random forest model can be explained by visualization of decision trees or by using measures of variable importance.

The models of Alnus and Betula had, at the least, considerable values of model evaluation statistics. More than $81 \%$ of events with high Betula pollen concentration could be predicted at each of the given 


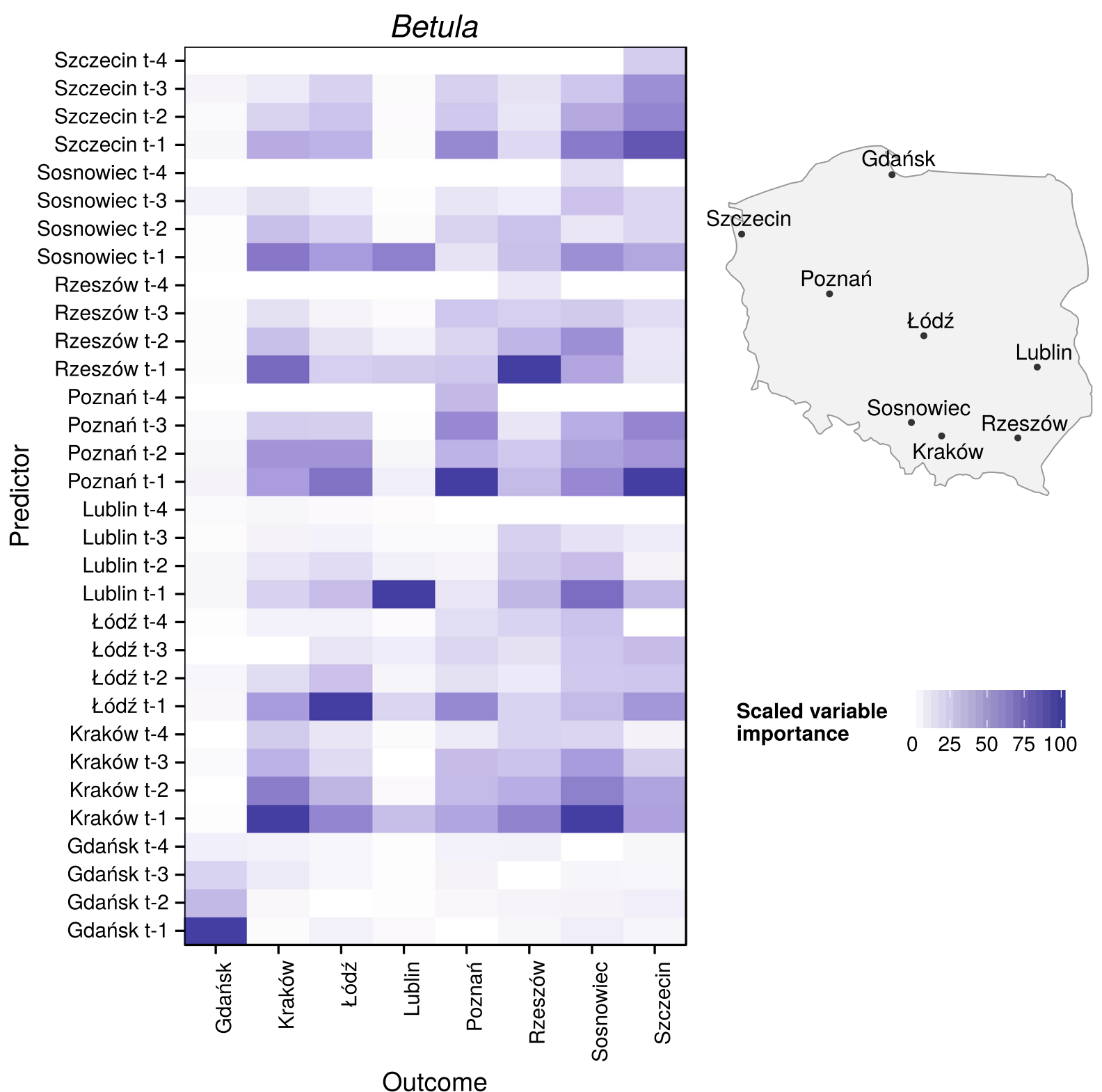

Fig. 5 Scaled variable importance of each predictor (pollen count data with 1-day lag $(t-1), 2$-day lag $(t-2), 3$-day lag $(t-3)$, 4-day lag $(t-4)$ at given sites) for Betula in each

sites. The models for Corylus showed low values of performance statistics in most cases. There are a few possible explanations for this. Firstly, there were insufficient events with high pollen concentration levels in the training/test sets and small values of Corylus pollen count generally. In the years 20032005 and 2009-2011, high Corylus pollen counts occurred only between 6 and 43 times (26 on average), location. For better spatial relations recognition, a schematic map with measurement sites was provided

and Corylus pollen concentration was lower than 19 grains $/ \mathrm{m}^{3}$ on $90 \%$ of the analyzed days. Secondly, Corylus models could be highly overfit, possibly due to a relatively short time series. The start and course of Corylus pollen season strongly depends on the type of habitat. Corylus pollen season starts sooner in sunny locations and cities, where only a few degrees above zero are enough to start the pollination. On the 
Fig. 6 Variations of the variables importance for each lag for Corylus, Alnus, and Betula models. The same site: only data from the same site. The other sites: all data except from the same site, and all data
The same site

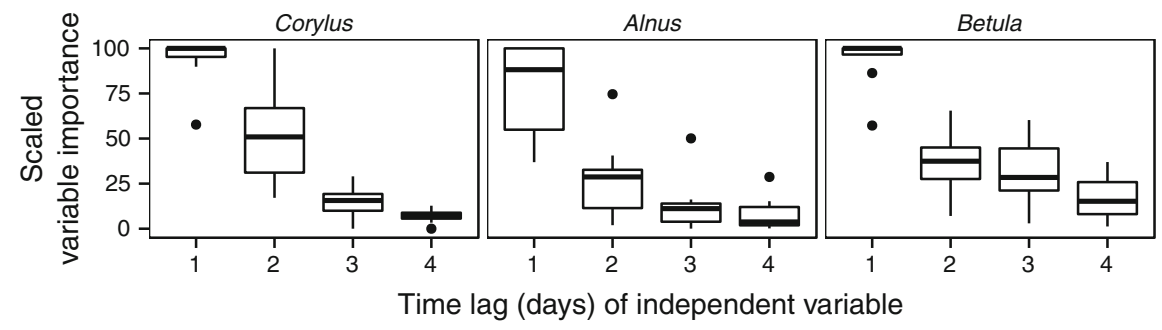

The other sites

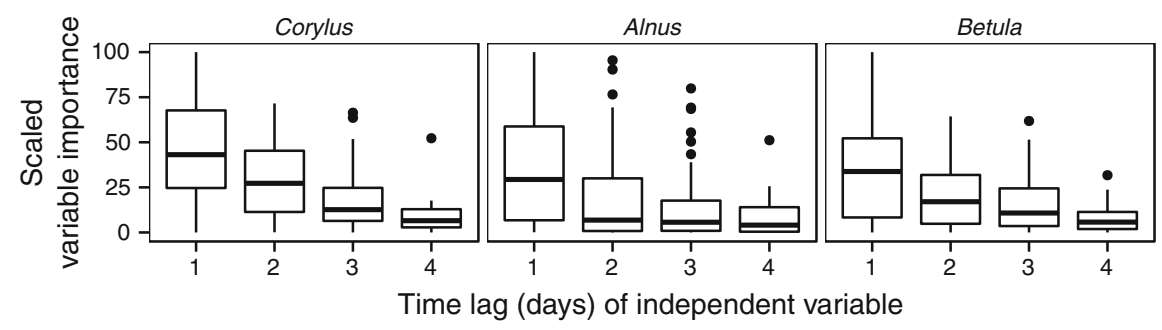

All data

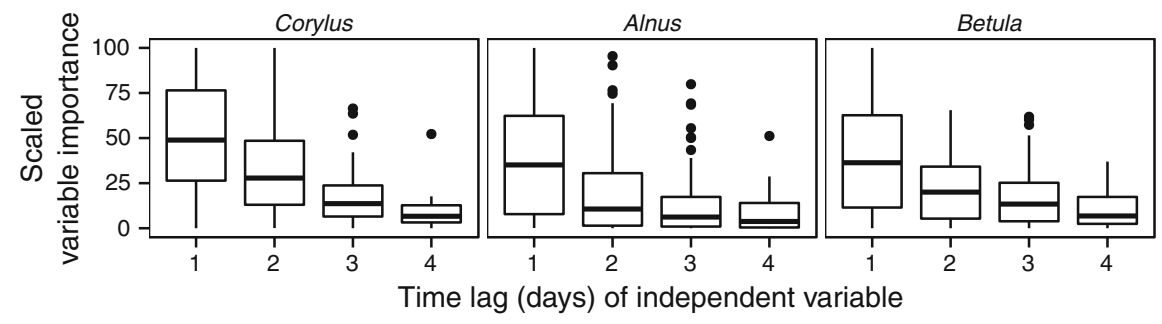

contrary, Corylus pollen season starts later in the sunless sites or forests. Therefore, its pollen season lasts longer than Alnus or Betula (Puc and Kasprzyk 2013). The pollen season of Alnus starts on average one weeks after Corylus in Poland (Nowosad et al. 2015). Alnus is also less common in the cities, and its start of flowering is less changeable between trees (Bugała 2000; Puc and Kasprzyk 2013). As a result, the relationship between Corylus pollen data in different cities is more complex than Alnus or Betula. Longer time series could reveal more information about Corylus spatiotemporal properties. Therefore, the variable importance of Corylus models should be interpreted with caution.

In this study, the model for Betula correctly forecasted between 81 and $95 \%$ of the days with high pollen concentrations in the test set. This model performance is similar to the previous work of Castellano-Méndez et al. (2005), who used artificial neural networks for predicting whether Betula pollen concentrations exceed certain thresholds-20, 30, 70, and $80 \mathrm{~g} / \mathrm{m}^{3}$ - using previous pollen and meteorological information. The artificial neural networks model predicted between 83 and $100 \%$ of overlevel pollen days on the validation set (years 2000 and 2001). Thus, the models based on previous pollen counts from several sites could serve as an alternative to models based on pollen and meteorological data from a single analyzed site.

The importance of independent variables showed a clear temporal and spatial dependency. In 23 of 24 models, variables from a day before had the largest impact. Moreover, input from the same site as the output was the most important in 16 of 24 models. In Alnus models, a high impact of variables from Poznań on Łódź, Sosnowiec, and Kraków was observed. This relationship was also found for Betula models. At the same time, in Betula models, aside from those at Szczecin and Sosnowiec, the input values from the nearest sites had clear importance; for example, Rzeszów and Sosnowiec for Kraków; Poznań for Łódź; Szczecin and Łódź for Poznań; and Poznań for Szczecin. One possible explanation is that neighboring stations have similar weather conditions and therefore 


\begin{tabular}{|c|c|c|c|c|c|c|c|c|c|}
\hline & \multicolumn{3}{|c|}{ Corylus } & \multicolumn{3}{|c|}{ Alnus } & \multicolumn{3}{|c|}{ Betula } \\
\hline high - & 2 & 0 & 0 & 6 & 7 & 0.54 & 6 & 31 & 0.84 \\
\hline low - & 146 & 0 & 1 & 114 & 2 & 0.98 & 34 & 3 & 0.92 \\
\hline high - & 5 & 6 & 0.55 & 5 & 12 & 0.71 & 6 & 42 & 0.88 \\
\hline low - & 133 & 4 & 0.97 & 111 & 2 & 0.98 & 26 & 1 & 0.96 \\
\hline high - & 4 & 1 & 0.2 & 3 & 14 & 0.82 & 8 & 34 & 0.81 \\
\hline low - & 141 & 2 & 0.99 & 111 & 1 & 0.99 & 28 & 4 & 0.88 \\
\hline $\bar{\Phi}$ high - & 4 & 10 & 0.71 & 3 & 22 & 0.88 & 6 & 39 & 0.87 \\
\hline low - & 130 & 4 & 0.97 & 95 & 10 & 0.9 & 25 & 4 & 0.86 \\
\hline$\frac{2}{d}$ high & 6 & 0 & 0 & 6 & 19 & 0.76 & 4 & 47 & 0.92 \\
\hline 5 low - & 142 & 0 & 1 & 99 & 5 & 0.95 & 20 & 4 & 0.83 \\
\hline high - & 3 & 5 & 0.62 & 5 & 12 & 0.71 & 4 & 35 & 0.9 \\
\hline low - & 134 & 6 & 0.96 & 107 & 5 & 0.96 & 27 & 8 & 0.77 \\
\hline high - & 5 & 5 & 0.5 & 6 & 11 & 0.65 & 2 & 39 & 0.95 \\
\hline low - & 134 & 4 & 0.97 & 110 & 3 & 0.97 & 29 & 5 & 0.85 \\
\hline high - & 7 & 3 & 0.3 & 7 & 24 & 0.77 & 7 & 41 & 0.85 \\
\hline low - & 137 & 1 & 0.99 & 89 & 10 & 0.9 & 20 & 6 & 0.77 \\
\hline & low & high & $\begin{array}{l}\text { specificit) } \\
\text { sensitivit }\end{array}$ & low & high & $\begin{array}{l}\text { specifici } \\
\text { sensitivi }\end{array}$ & low & high & $\begin{array}{l}\text { pecificit } \\
\text { ensitivit }\end{array}$ \\
\hline
\end{tabular}

Fig. 7 Confusion matrices and specificity/sensitivity for test sets of pollen concentration level prediction for Corylus, Alnus, and Betula at each location

similar pollen emission. The other explanation is influence of long-distance transport caused by the dominant westerly direction of winds in Poland. After a one-day lag, the variable importance noticeably decreases. It was found that variables from 4 days before show the least importance, with average values of 10.52, 8.58, and $8.67 \%$ for Corylus, Alnus, and Betula, respectively, and the highest values did not exceed $50 \%$. This could be associated with the inflow of a new air mass with different physical characteristics from the previous one. In Poland, the variability of most strings of days with a single air mass type was determined to be between 1 and 3 days (Kotas et al. 2013). It should be noted that variable importance is not a measure of causation.

Pollen production and dispersion is affected by many factors: regional flora, land use, vegetation structure, topoclimate, and weather conditions. Pollen 
Table 4 A summary of Corylus, Alnus, and Betula models results for test set at each location

\begin{tabular}{|c|c|c|c|c|c|}
\hline Taxon & City & Карра & Balanced accuracy & Sensitivity & Specificity \\
\hline Corylus & Gdańsk & 0.00 & 0.50 & 1.00 & 0.00 \\
\hline Corylus & Kraków & 0.54 & 0.76 & 0.97 & 0.55 \\
\hline Corylus & Lublin & 0.68 & 0.84 & 0.97 & 0.71 \\
\hline Corylus & Łódź & 0.23 & 0.59 & 0.99 & 0.20 \\
\hline Corylus & Poznań & 0.00 & 0.50 & 1.00 & 0.00 \\
\hline Corylus & Rzeszów & 0.49 & 0.79 & 0.96 & 0.62 \\
\hline Corylus & Sosnowiec & 0.49 & 0.74 & 0.97 & 0.50 \\
\hline Corylus & Szczecin & 0.41 & 0.65 & 0.99 & 0.30 \\
\hline Alnus & Gdańsk & 0.60 & 0.76 & 0.98 & 0.54 \\
\hline Alnus & Kraków & 0.74 & 0.84 & 0.98 & 0.71 \\
\hline Alnus & Lublin & 0.71 & 0.89 & 0.90 & 0.88 \\
\hline Alnus & Łódź & 0.86 & 0.91 & 0.99 & 0.82 \\
\hline Alnus & Poznań & 0.72 & 0.86 & 0.95 & 0.76 \\
\hline Alnus & Rzeszów & 0.66 & 0.83 & 0.96 & 0.71 \\
\hline Alnus & Sosnowiec & 0.67 & 0.81 & 0.97 & 0.65 \\
\hline Alnus & Szczecin & 0.65 & 0.84 & 0.90 & 0.77 \\
\hline Betula & Gdańsk & 0.76 & 0.88 & 0.92 & 0.84 \\
\hline Betula & Kraków & 0.81 & 0.92 & 0.96 & 0.88 \\
\hline Betula & Lublin & 0.72 & 0.86 & 0.86 & 0.87 \\
\hline Betula & Łódź & 0.67 & 0.84 & 0.88 & 0.81 \\
\hline Betula & Poznań & 0.75 & 0.88 & 0.83 & 0.92 \\
\hline Betula & Rzeszów & 0.67 & 0.83 & 0.77 & 0.90 \\
\hline Betula & Sosnowiec & 0.81 & 0.90 & 0.85 & 0.95 \\
\hline Betula & Szczecin & 0.62 & 0.81 & 0.77 & 0.85 \\
\hline
\end{tabular}

concentration in air cannot be described as a linear effect of the impact of these factors. Despite the fact that Alnus and Betula models had substantial prediction quality, some of the events of low or high pollen level were wrongly classified. This is connected mainly with unusual events, such as no pollen or low pollen concentration at monitoring sites on the days before and high pollen count at a given site. Or it may be the opposite: low pollen concentration at a given site and high pollen count at monitoring sites in the preceding days. The occurrence of these situations can be partially explained by the influence of atmospheric conditions. The pollen concentration level could be low during the rainfall and high on the next day with a dry weather. The rapid day-to-day temperature changes also can be the cause of the models errors. Additionally, the occurrence of wrongly classified cases could probably be explained by other factors, such as random local events or changes in scale smaller than those analyzed.
Gdańsk distinguished itself from the other sites. Days with high pollen concentration of Corylus, Alnus, and Betula were less frequent there. In most of the models, independent variables from Gdańsk had little or no importance. Moreover, the prediction quality for Gdańsk was the lowest in the Corylus and Alnus models. As has been reported previously (Nowosad et al. 2015), Gdańsk has different pollen characteristics from other Polish sites. Its northern, coastal location has an impact on the local climate, and the start of the growing season is usually delayed there.

\section{Conclusions}

In this study, data from eight Polish monitoring sites over six years were used. The final 24 models are not necessarily the best ones in terms of prediction quality. The Corylus models performed poorly, which could be 
a mixed result of (1) insufficient events with high pollen concentration level in the training/test set, (2) highly overfit models, and (3) fast change of pollen autocorrelation drop.

On the other hand, the study has clearly shown that it is possible to predict the occurrence of days with high pollen concentration of Alnus and Betula using past pollen count data from monitoring sites. For these taxa, random forest models offer capabilities for forecasting pollen concentration levels, with substantial accuracy. The models are an alternative to pollen concentration models based on weather conditions, and they show promise as a useful source of information on high pollen concentration levels for allergists and their patients. It would thus be worthwhile to combine two groups of independent variables-meteorological and aerobiological-from several sites to improve models for predicting pollen concentrations which exceed threshold values. An analysis of longer time periods or a denser monitoring network could also result in better model quality, especially in the case of Corylus.

Acknowledgments This study was carried out within the framework of the Project No. NN305 321936 financed by the Ministry of Science and Higher Education.

Open Access This article is distributed under the terms of the Creative Commons Attribution 4.0 International License (http:// creativecommons.org/licenses/by/4.0/), which permits unrestricted use, distribution, and reproduction in any medium, provided you give appropriate credit to the original author(s) and the source, provide a link to the Creative Commons license, and indicate if changes were made.

\section{References}

Blazejczyk, K. (2006). Climate and bioclimate of Poland. In Degórski EM (Ed.). Natural and human environment of Poland. A geographical overview (pp. 31-48). Warsaw: Polish Academy of Sciences, Inst. of Geography and Spatial Organization Polish Geographical Society.

Boucher, A., Hidalgo, P. J., Thonnat, M., Belmonte, J., Galan, C., Bonton, P., et al. (2002). Development of a semi-automatic system for pollen recognition. Aerobiologia, 18(3), 195-201. doi:10.1023/A:1021322813565.

Breiman, L. (2001). Random forests. Machine Learning, 45(1), 5-32. doi:10.1023/A:1010933404324.

Breiman, L. (2002). Manual on setting up, using, and understanding random forests v3.1.
Bremer, B., Bremer, K., \& Chase, M. (2009). An update of the Angiosperm Phylogeny Group classification for the orders and families of flowering plants: APG III. Botanical Journal of the Linnean Society, 161(2), 105-121.

Bringfelt, B., Engström, I., \& Nilsson, S. (1982). An evaluation of some models to predict airborne pollen concentration from meteorological conditions in Stockholm, Sweden. Grana, 21(1), 59-64. doi:10.1080/00173138209427680.

Bugała, W. (2000). Drzewa i krzewy (Trees and shrubbery). Państwowe Wydawnictwo Rolnicze i Leśne PWRiL (in Polish).

Cariñanos, P., \& Emberlin, J. (2000). Comparison of two pollen counting methods of slides from a Hirst type volumetric trap. Aerobiologia, 16, 339-346.

Castellano-Méndez, M., Aira, M. J., Iglesias, I., Jato, V., \& González-Manteiga, W. (2005). Artificial neural networks as a useful tool to predict the risk level of Betula pollen in the air. International Journal of Biometeorology, 49(5), 310-6. doi:10.1007/s00484-004-0247-x.

Comtois, P. (1998). Statistical analysis of aerobiological data. In P. Mandrioli, P. Comtois, \& V. Levizzani (Eds.), Methods in aerobiology. Bologna: Pitagora Editrice.

Cotos-Yáñez, T. R., Rodríguez-Rajo, F. J., \& Jato, M. V. (2004). Short-term prediction of Betula airborne pollen concentration in Vigo (NW Spain) using logistic additive models and partially linear models. International Journal of Biometeorology, 48(4), 179-85. doi:10.1007/s00484-0040203-9.

Dmochowska, H. (Ed.). (2013). Concise Statistical Yearbook of Poland 2013. Poland: Statistical Publishing Establishment.

Galán, C., Cariñanos, P., Alcázar, P., \& Dominguez-Vilches, E. (2007). Spanish aerobiology network (REA) management and quality manual. Servicio de Publicaciones Universidad de Córdoba. Tech. rep., ISBN 978-84-690-6353-8.

Galán, C., Smith, M., Thibaudon, M., Frenguelli, G., Oteros, J., Gehrig, R., et al. (2014). Pollen monitoring: Minimum requirements and reproducibility of analysis. Aerobiologia, 30(4), 385-395. doi:10.1007/s10453-014-9335-5.

Geurts, P., Irrthum, A., \& Wehenkel, L. (2009). Supervised learning with decision tree-based methods in computational and systems biology. Molecular Biosystems, 5, 1593-1605. doi:10.1039/b907946g.

Heinzerling, L. M., Burbach, G. J., Edenharter, G., Bachert, C., Bindslev-Jensen, C., Bonini, S., et al. (2009). GA(2)LEN skin test study I: GA(2)LEN harmonization of skin prick testing: Novel sensitization patterns for inhalant allergens in Europe. Allergy, 64(10), 1498-1506. doi:10.1111/j. 1398-9995.2009.02093.x.

Hilaire, D., Rotach, M. M. W., \& Clot, B. (2012). Building models for daily pollen concentrations. Aerobiologia, 28(4), 499-513. doi:10.1007/s10453-012-9252-4.

Hirst, J. M. (1952). An automatic volumetric spore trap. Annals of Applied Biology, 39(2), 257-265. doi:10.1111/j.17447348.1952.tb00904.x.

Holt, K. A., \& Bennett, K. D. (2014). Principles and methods for automated palynology. New Phytologist, 203(3), 735-742. doi:10.1111/nph.12848.

Kornas, J., \& Medwecka-Kornas, A. (2002). Geografia roślin (Plant geography). Warszawa: Wydawnictwo Naukowe PWN. (in Polish). 
Kotas, P., Twardosz, R., \& Nieckarz, Z. (2013). Variability of air mass occurrence in southern Poland (1951-2010). Theoretical and Applied Climatology, 114(3-4), 615-623. doi:10.1007/s00704-013-0861-9.

Kuhn, M. (2014). caret: Classification and regression training. http://cran.r-project.org/package=caret

Kuhn, M., \& Johnson, K. (2013). Applied predictive modeling. New York: Springer.

Latałowa, M., Miętus, M., \& Uruska, A. (2002). Seasonal variations in the atmospheric Betula pollen count in Gdańsk (southern Baltic coast) in relation to meteorological parameters. Aerobiologia, 18, 33-43.

Liaw, A., \& Wiener, M. (2002). Classification and regression by random forest. $R$ News, 2(3), 18-22.

Mann, H. B., \& Whitney, D. R. (1947). On a test of whether one of two random variables is stochastically larger than the other. The Annals of Mathematical Statistics, 18(1), 50-60. doi:10.1214/aoms/1177730491.

Myszkowska, D. (2013). Prediction of the birch pollen season characteristics in Cracow, Poland using an 18-year data series. Aerobiologia, 29(1), 31-44. doi:10.1007/s10453012-9260-4.

Nilsson, S., \& Persson, S. (1981). Tree pollen spectra in the Stockholm region (Sweden), 1973-1980. Grana, 20(3), 179-182. doi:10.1080/00173138109427661.

Nowosad, J., Stach, A., Kasprzyk, I., Latałowa, M., Puc, M., Myszkowska, D., et al. (2015). Temporal and spatiotemporal autocorrelation of daily concentrations of Alnus, Betula, and Corylus pollen in Poland. Aerobiologia, 31, 159-177. doi:10.1007/s10453-014-9354-2.

Puc, M. (2012). Artificial neural network model of the relationship between Betula pollen and meteorological factors in Szczecin (Poland). International Journal of Biometeorology, 56(2), 395-401. doi:10.1007/s00484-011-0446-1.

Puc, M., \& Kasprzyk, I. (2013). The patterns of Corylus and Alnus pollen seasons and pollination periods in two Polish cities located in different climatic regions. Aerobiologia, 29, 495-511. doi:10.1007/s10453-013-9299-x.

R Core Team. (2014). R: A language and environment for statistical computing. R Foundation for Statistical Computing, Vienna, Austria, http://www.r-project.org/
Rapiejko, P., Stankiewicz, W., Szczygielski, K., \& Jurkiewicz, D. (2007). Progowe stężenie pyłku roślin niezbędne do wywołania objawów alergicznych (Threshold pollen count necessary to evoke allergic symptoms). Otolaryngologia Polska, 61(4), 591-594. doi:10.1016/S0030-6657(07) 70491-2.

Recknagel, F. (2001). Applications of machine learning to ecological modelling. Ecological Modelling, 146, 303-310. doi:10.1016/S0304-3800(01)00316-7.

Rodriguez-Rajo, F., Rodríguez-Rajo, F. J., Valencia-Barrera, R. M., Vega-Maray, A. M., Suárez, F. J., Fernández-González, D., et al. (2006). Prediction of airborne Alnus pollen concentration by using ARIMA models. Annals of Agricultural and Environmental Medicine, 13(1), 25-32.

Sofiev, M., Siljamo, P., Ranta, H., Linkosalo, T., Jaeger, S., Rasmussen, A., et al. (2013). A numerical model of birch pollen emission and dispersion in the atmosphere. Description of the emission module. International Journal of Biometeorology, 57(1), 45-58. doi:10.1007/s00484012-0532-z.

Stach, A. (2000). Variation in pollen concentration of the most allergenic taxa in Poznań (Poland), 1995-1996. Aerobiologia, 16(1), 63-68. doi:10.1023/A:1007603019797.

Valenta, R., Breiteneder, H., Pettenburger, K., Breitenbach, M., Rumpold, H., Kraft, D., et al. (1991). Homology of the major birch-pollen allergen, I, with the major pollen allergens of alder, hazel, and hornbeam at the nucleic acid level as determined by cross-hybridization. Journal of Allergy and Clinical Immunology, 87(3), 677-682. doi:10. 1016/0091-6749(91)90388-5.

Viander, M., \& Koivikko, A. (1978). The seasonal symptoms of hyposensitized and untreated hay fever patients in relation to birch pollen counts: correlations with nasal sensitivity, prick tests and RAST. Clinical \& Experimental Allergy, 8(4), 387-396.

Vogel, H., Pauling, A., \& Vogel, B. (2008). Numerical simulation of birch pollen dispersion with an operational weather forecast system. International Journal of Biometeorology, 52(8), 805-814. doi:10.1007/s00484-008-0174-3. 